\title{
Transition metal containing ionic liquid-assisted one-pot synthesis of pyrazoles at room temperature
}

\author{
MANASHJYOTI KONWAR ${ }^{\mathrm{a}}$, HANAN M F ELNAGDY ${ }^{\mathrm{a}}$, PRAVEEN SINGH GEHLOT $^{\mathrm{b}}$, \\ NAGESHWAR D KHUPSE ${ }^{c}$, ARVIND KUMAR $^{b, *}$ and DIGANTA SARMA ${ }^{a, *}$ (D) \\ ${ }^{a}$ Department of Chemistry, Dibrugarh University, Dibrugarh 786 004, Assam, India \\ ${ }^{b}$ Academy of Scientific and Innovative Research (AcSIR)-Central Salt and Marine Chemicals Research \\ Institute, Council of Scientific and Industrial Research (CSIR), G. B. Marg, Bhavnagar 364 002, Gujarat, \\ India \\ ${ }^{\mathrm{c}}$ Centre for Materials for Electronics Technology, Pashan Road, Pune 411 008, Maharashtra, India \\ E-mail: arvind@csmcri.res.in; dsarma22@dibru.ac.in
}

MS received 14 May 2019; revised 16 June 2019; accepted 23 June 2019

\begin{abstract}
The feasible and one of the green ways to synthesize organic compounds especially pyrazole and its derivatives are systematically presented. The one-pot synthesis of pyrazole was achieved by condensation of various hydrazines and 1,3-diketone derivatives at room temperature using transition metal-based ionic liquids. Herein, the unique combination of Fe(III) with ionic liquid is explored and utilized as an efficient homogeneous catalyst for the synthesis of pyrazole and its derivatives. The homogenous catalyst thus synthesised was re-used up to the fourth cycle (with $90 \%, 88 \%, 84 \%, 78 \%$ yields respectively).
\end{abstract}

Keywords. 1,3-Diketone; hydrazine; green chemistry; pyrazole; transition metal; paramagnetic ionic liquids.

\section{Introduction}

In organic synthesis, various toxic solvents and expensive catalysts prepared by tedious multistep reactions are generally used. To eliminate the hazards associated with routine organic synthesis we propose here a simple method to synthesize organic compounds keeping the principles of green chemistry on top priority. The use of ionic liquids (ILs) as catalyst or solvent is a part of the hazard-free chemical process, which has been used extensively in research fields. Thus, ILs gain escalating attention for their expansive range of applications as prospective replacements for volatile organic solvents. ${ }^{1-3}$ The physicochemical properties of ILs have been wellstudied. Different noteworthy ILs have been developed by means of appropriate exchange of cations and anions. $^{4,5}$ ILs have achieved special attention as a potential green solvent because they have remarkable physiological properties including a broad range of solubility, very low volatility, inflammability, excellent thermal stability, non-corrosive towards metals and good conductivity. ${ }^{6-11}$ Because of the adjustable physical properties, ionic liquids have been used in various organic transformations including pyrazole synthesis. ${ }^{12-16}$ The judicial choice of counterion in ionic liquids makes them green and more suitable as catalyst or solvent or both for many organic processes, as they increase the optimum possibility such as homogenous distribution of reactants, controllable product formation, jump in reactivity or rate of reaction, ease of product isolation and recycling. ${ }^{17}$

The ionic liquids with metal ion are a new subclass of task-specific ionic liquids since they have both magnetic and catalytic property. Most of the metal-based ionic liquids have been reported earlier with transition metal ion $\left(\mathrm{M}^{\mathrm{n}+}\right)$ with various counter ions including halides $\left(\mathrm{X}^{-}\right), \mathrm{SCN}^{-}, \mathrm{Tf}_{2} \mathrm{~N}^{-}$ions, etc. ${ }^{18}$ Metal ion as a counterpart of the ionic liquid provides superior catalytic media due to the elevated effectual concentrations of metal ions

*For correspondence

Electronic supplementary material: The online version of this article (https://doi.org/10.1007/s12039-019-1659-9) contains supplementary material, which is available to authorized users. 
and their Lewis acidic nature. ${ }^{19-24}$ The presence of such high effective transition metal ion concentrations in this kind of ILs also termed as paramagnetic liquids, does not alter the properties of ILs such as low volatility, hydrophilicity, electrical conductivity, etc.

There are numerous reports from various research groups describing metal-based ionic liquids including transition metals such as $\left[\mathrm{Al}_{\mathrm{x}} \mathrm{Cl}_{\mathrm{y}}\right]^{-},\left[\mathrm{FeCl}_{4}\right]^{-},\left[\mathrm{MnCl}_{4}\right]^{2-}$ $\left[\mathrm{CuCl}_{4}\right]^{2-},\left[\mathrm{NiCl}_{4}\right]^{2-},\left[\mathrm{PdCl}_{4}\right]^{2-}$, etc. ${ }^{25,26}$ Most of reported imidazolium-based transition metal ILs are solid at room temperature, except $\left[\mathrm{FeCl}_{4}\right]^{-}$salts which are liquid at room temperature due to its tetrahedral lattice breaking structure. In continuation of our interest in exploring the green and feasible synthetic route for various organic transformation, in this manuscript, we have used paramagnetic anion $\left[\mathrm{FeCl}_{4}\right]^{-}$bearing ionic liquid as an efficient catalyst for pyrazole synthesis.

Due to the medicinal importance, pyrazole core gains immense significance in the pharmacological industry for drug design such as anticancer, antibacterial, antimicrobial, antifungal, etc. ${ }^{27-30}$ Because of the presence of lone pairs in the nitrogen atoms, pyrazole moiety itself acts as ligands for catalysis. ${ }^{31-33}$ Pyrazole is also known to act as a precursor of agro-based chemicals as pesticides, herbicides, fungicides, etc. ${ }^{34-36}$ Pyrazole moieties also have some other applications in industrial and material sciences such as ultraviolet stabilizer, ${ }^{37}$ optical brighteners, ${ }^{38}$ selective fluorescence sensors, ${ }^{39}$ luminescent complexes, etc. ${ }^{40,41}$ Among various procedures for the synthesis of pyrazoles, the condensation of hydrazine derivatives with 1,3-diketones is a widely utilized technique ${ }^{42,43}$ over other reaction procedures which are associated with several disadvantages such as prolong reaction time, elevated temperature, use of costly ligands, multistep preparation of the substrate, formation of tautomers and conformers, etc. $^{44-47}$ In addition, the formation of numerous regioisomeric mixtures of pyrazoles was frequent while carrying out the synthesis making the system more cumbersome. ${ }^{48,49}$ Literature reports reveal the use of several kinds of homogeneous catalysts, ${ }^{50,51}$ heterogeneous catalysts, ${ }^{52-54}$ different metal sources, ${ }^{55,56}$ micellar catalyst, ${ }^{57}$ nano ionic liquids, ${ }^{58}$ enzymatic catalyst, ${ }^{59}$ etc., for the synthesis of pyrazole through different reaction routes such as ultrasound, ${ }^{60}$ microwave, ${ }^{61}$ neat, ${ }^{62}$ using different substrates, etc.

\section{Experimental}

All reagents and solvents were purchased from Sigma Aldrich, Merck and Alfa Aesar and used without further purification unless otherwise stated. All reported yields are isolated yields. Pyrazole synthesis was performed on oven-dried glassware at open air. ${ }^{1} \mathrm{H}$ and ${ }^{13} \mathrm{C}$ NMR spectra were recorded on $200 \mathrm{MHz}$ and $50 \mathrm{MHz}$ or 500 $\mathrm{MHz}$ and $125 \mathrm{MHz}$ spectrometers at room temperature. Chemical shifts are reported in parts per million (ppm, $\delta$ ). Column chromatography was performed on silica gel (120-230 mesh). Thin-layer chromatography (TLC) was carried out using aluminium sheets pre-coated with silica gel $60 \mathrm{~F}_{254}$ (Merck) and was visualized under $254 \mathrm{~nm} \mathrm{UV}$ light.

\subsection{Procedures}

2.1a Synthesis and characterization of catalysts: The transition metal-based ionic liquids, $\left[\mathrm{C}_{4} \mathrm{mim}\right]_{2}\left[\mathrm{MnCl}_{4}\right]$ and $\left[\mathrm{C}_{4} \mathrm{mim}\right]\left[\mathrm{FeCl}_{4}\right]$ were synthesized according to reported literature. These ionic liquids were characterized by using different analytical techniques such as ESI-MS, DSC and TGA, UV and Raman spectra for anion, ICP-OES data for percentage metal content.

2.1b Synthesis of transition metal-based ionic liquids: The synthesis of transition metal-based ionic liquids is carried out according to previously reported procedure. $^{23,63,64}$

(i) $\left[\mathbf{C}_{\mathbf{4}} \mathbf{m i m}\right]\left[\mathrm{FeCl}_{\mathbf{4}}\right]$ : To synthesize the $\left[\mathrm{C}_{4} \mathrm{mim}\right]\left[\mathrm{FeCl}_{4}\right]$, 1-butyl-3-methyl imidazolium chloride $\left(\left[\mathrm{C}_{4} \mathrm{mim}\right] \mathrm{Cl}\right)(5 \mathrm{~g}$, $28.63 \mathrm{mmol})$ and ferric chloride hexahydrate $\left(\mathrm{FeCl}_{3} \cdot 6 \mathrm{H}_{2} \mathrm{O}\right)$ $(8.5 \mathrm{~g}, 31.89 \mathrm{mmol})$ were taken in $100 \mathrm{~mL}$ round bottom flask with 1:1.1 molar ratio in methanol. The reaction mixture was refluxed for $24 \mathrm{~h}$. After completion of the reaction, the solvent was removed from the product using rotary evaporator. The product was washed with a little amount of $\mathrm{MQ}$ water to remove unreacted $\mathrm{FeCl}_{3}$. The dark brown product was again dried using rotary evaporator and stored in a vacuum oven. Mass analysis was done in MicroMass Q-TOF instrument using methanol as solvent. Observed Mass Spectral data: $\mathrm{ESI}^{+} \mathrm{m} / \mathrm{z}$ for $\left[\mathrm{C}_{4} \mathrm{mim}\right]^{+}=$ 139.23, 140.23, ESI $^{-} \mathrm{m} / \mathrm{z}$ for $\left[\mathrm{FeCl}_{4}\right]^{-}=195.91,197.57$ $(100 \%)$ and 199.91. Percentage of Fe content in the IL was determined by ICP-OES (Inductively Coupled Plasma-Optical Emission Spectroscopy) analysis in Perkin Elmer ICP optima 2000 DV ICP-OES analyzer and it was found that $\mathrm{Fe}$ content in $\left[\mathrm{C}_{4} \mathrm{mim}\right]\left[\mathrm{FeCl}_{4}\right]$ is $14 \%$.

(ii) $\left[\mathbf{C}_{4} \mathbf{m i m}\right]_{2}\left[\mathbf{M n C l}_{4}\right]$ : For $\left[\mathrm{C}_{4} \mathrm{mim}\right]_{2}\left[\mathrm{MnCl}_{4}\right]$, 1-butyl3-methyl imidazolium chloride $\left(\left[\mathrm{C}_{4} \mathrm{mim}\right] \mathrm{Cl}\right)(5 \mathrm{~g}, 28.63$ mmol) and manganese chloride tetrahydrate $\left(\mathrm{MnCl}_{2} \cdot 4 \mathrm{H}_{2} \mathrm{O}\right)$ $(2.7 \mathrm{~g}, 13.63 \mathrm{mmol})$ were taken in $100 \mathrm{~mL}$ round bottom flask with 2.1:1 molar ratio in methanol. The reaction mixture was refluxed for $24 \mathrm{~h}$. After completion of the reaction, the solvent was removed from the product using rotary evaporator. The product was washed with isopropyl alcohol to remove unreacted $\left[\mathrm{C}_{4} \mathrm{mim}\right] \mathrm{Cl}$. The faint yellowgreen coloured product was again dried using rotary evaporator and stored in a vacuum oven. Mass analysis was done in MicroMass Q-TOF instrument using methanol as a solvent. Observed Mass Spectral data: $\mathrm{ESI}^{+} \mathrm{m} / \mathrm{z}$ for $\left[\mathrm{C}_{4} \mathrm{mim}\right]^{+}$ $=139.24,140.25, \mathrm{ESI}^{-} \mathrm{m} / \mathrm{z}$ for $\left[\mathrm{MnCl}_{4}\right]^{-}=195.59,196.02$ 

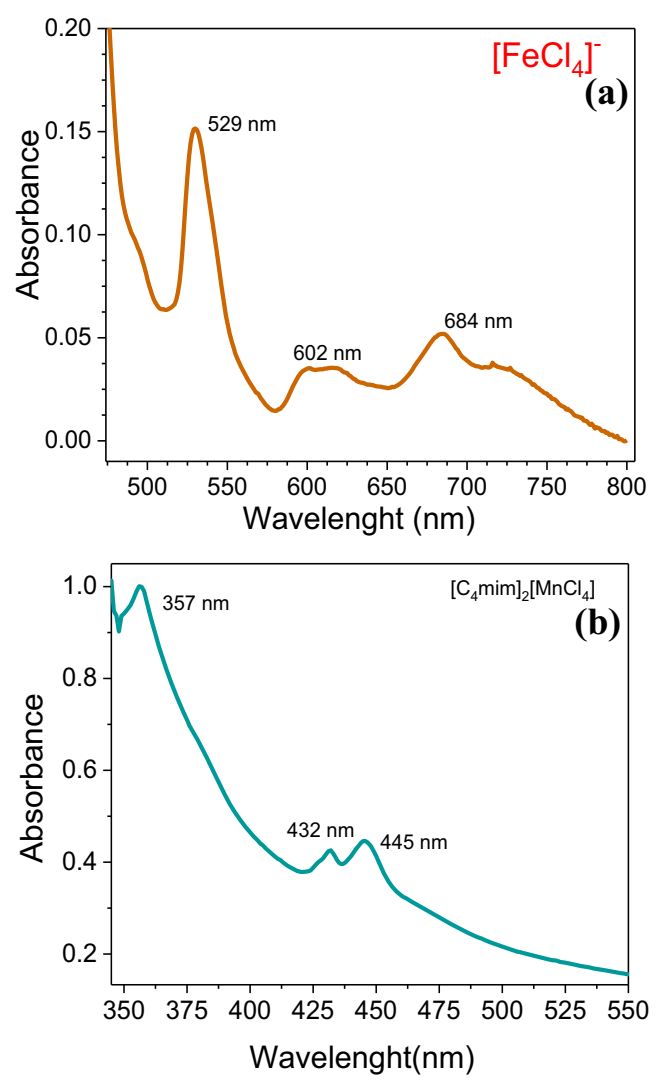

Figure 1. UV-Visible spectroscopy of the ionic liquid for (a) $\left[\mathrm{FeCl}_{4}\right]^{-}$anion and (b) $\left[\mathrm{MnCl}_{4}\right]^{-}$.
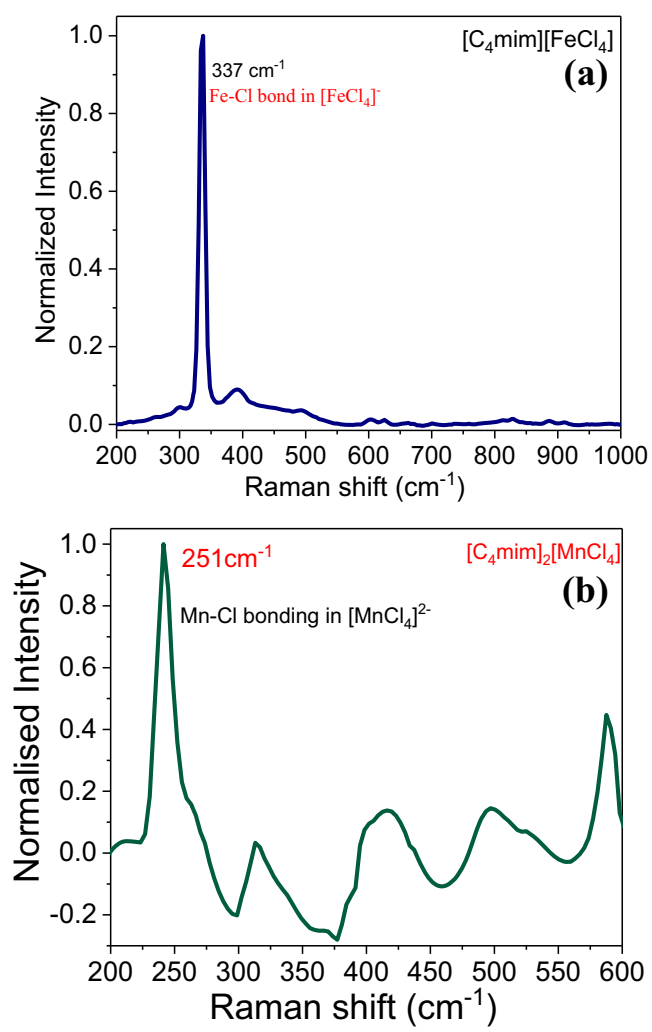

Figure 2. Raman spectra of the ionic liquids (a) $\left[\mathrm{C}_{4-}\right.$ $\operatorname{mim}]\left[\mathrm{FeCl}_{4}\right]$ and (b) $\left[\mathrm{C}_{4} \mathrm{mim}\right]_{2}\left[\mathrm{MnCl}_{4}\right]$.
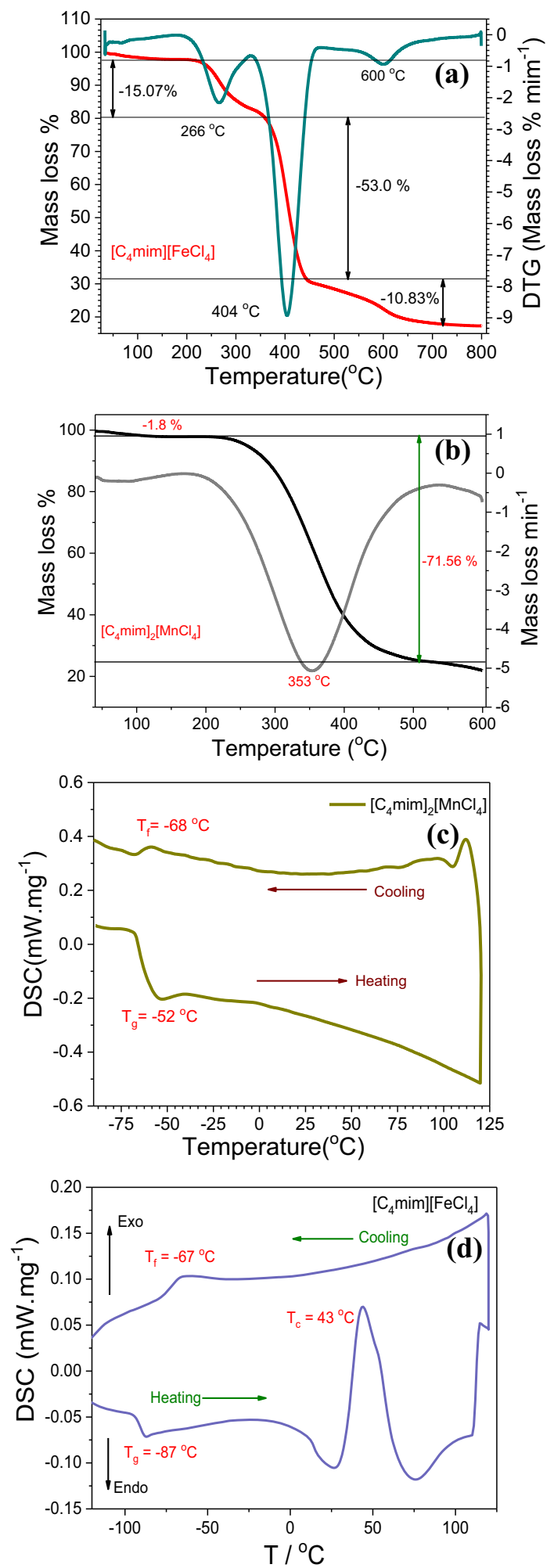

Figure 3. TGA of (a) $\left[\mathrm{C}_{4} \mathrm{mim}\right]\left[\mathrm{FeCl}_{4}\right]$ (b) $\left[\mathrm{C}_{4} \mathrm{mim}\right]_{2}[-$ $\left.\mathrm{MnCl}_{4}\right]$ and DSC of (c) $\left[\mathrm{C}_{4} \mathrm{mim}\right]\left[\mathrm{FeCl}_{4}\right]$ and (d) $\left[\mathrm{C}_{4} \mathrm{mim}\right]_{2}[-$ $\left.\mathrm{MnCl}_{4}\right]$ ILs.

(100\%), 196.04. The percentage of metal content in IL was determined by ICP-OES analysis and it was found that $\mathrm{Mn}$ content in $\left[\mathrm{C}_{4} \mathrm{mim}\right]_{2}\left[\mathrm{MnCl}_{4}\right]$ is $12 \%$. 


\subsection{Characterization of the transition metal- based ionic liquids}

2.2a $U V$ and Raman spectra for $\left[\mathrm{MCl}_{4}\right]$ anion: Structure elucidation of paramagnetic anions has been verified with UV-3600 Shimadzu UV-Vis-NIR absorption spectroscopy with quartz cuvette of $1 \mathrm{~cm}$ path length in the acetonitrile and LabRAM HR Evolutions (Horiba Jobin Yvon) Raman Spectroscopy. In Figure 1 (a), the characteristic bands for tetrachloroferrate(III) $\left(\left[\mathrm{FeCl}_{4}\right]^{-}\right)$anion has appeared in a range of 450 to $700 \mathrm{~nm}$. The characteristic peaks have appeared at 529, 602 and $684 \mathrm{~nm}$ were due to ${ }^{6} \mathrm{~A}_{1} \rightarrow{ }^{4} \mathrm{~T}_{2}$, ${ }^{6} \mathrm{~A}_{1} \rightarrow{ }^{4} \mathrm{~A}_{2}$, and ${ }^{6} \mathrm{~A}_{1} \rightarrow{ }^{4} \mathrm{~T}_{2}$ transition respectively. ${ }^{65}$

Similarly, in Figure 1 (b), the characteristic bands for tetrachloromanganate(II) $\left(\left[\mathrm{MnCl}_{4}\right]^{2-}\right)$ anion have appeared in a range of 300 to $600 \mathrm{~nm}$. The $\mathrm{Mn}$ (II) based ionic liquid shows one peak at $357 \mathrm{~nm}$ which is due to the transition from ${ }^{6} \mathrm{~A}_{1} \rightarrow{ }^{4} \mathrm{E}(\mathrm{D})$. The second weak band has appeared at $432 \mathrm{~nm}$ is due to ${ }^{6} \mathrm{~A}_{1} \rightarrow{ }^{4} \mathrm{~A}$, and just next to its peak at $445 \mathrm{~nm}$ is related to ${ }^{6} \mathrm{~A}_{1} \rightarrow{ }^{4} \mathrm{~T}_{2}$ transitions of a tetrahedral $\left[\mathrm{MnCl}_{4}\right]^{2-}$. 66

Further, the structures of $\left[\mathrm{FeCl}_{4}\right]^{-}$and $\left[\mathrm{MnCl}_{4}\right]^{2-}$ anions have been verified from Raman spectra shown in Figure 2 (a-b). The characteristic band has appeared at $337 \mathrm{~cm}^{-1}$ due to total symmetric vibration $\left(\mathrm{A}_{1}\right)$ mode in $\mathrm{Fe}-\mathrm{Cl}$ bond. ${ }^{67,68} \mathrm{It}$ is observed from the Raman spectrum of $\left[\mathrm{FeCl}_{4}\right]^{-}$(Figure 2 (a)) that there is no any additional intense peaks (except 337 $\mathrm{cm}^{-1}$ ) which eliminates the possibility of formation of the dimer $\left(\left[\mathrm{Fe}_{2} \mathrm{Cl}_{7}\right]^{-}\right)$. The characteristic band at $251 \mathrm{~cm}^{-1}$ has been assigned for symmetric vibration $\left(\mathrm{A}_{1}\right)$ mode in $\mathrm{Mn}-\mathrm{Cl}$ bond in tetrahedral $\left[\mathrm{MnCl}_{4}\right]^{2-}$ anion (Figure $\left.2(\mathbf{b})\right){ }^{66}$

2.2b DSC and TGA: Thermal behavior of ILs has been investigated by using NETZSCH DSC 204F1 Phonex 240-12-0239-L and NETZSCH TG 209 F1 Libra TGA 209F1D-0105-L instrument. DSC has been recorded with a rate of $10^{\circ} \mathrm{C} \min ^{-1}$ from -100 to $120{ }^{\circ} \mathrm{C}$ while for TGA, the scan rate was $10^{\circ} \mathrm{C} \mathrm{min}^{-1}$ from 30 to $600^{\circ} \mathrm{C}$. Figures 3 (a-b) and Figures 3 (c-d) shows thermal properties of ILs using
Thermal Gravimetric Analysis (TGA) and Differential Scanning Calorimeter (DSC) respectively. The DCS thermograms show its glass transition temperature $\left(T_{g}\right)$ and all the synthesized ILs have their glass transition temperature below room temperature which fulfill the criteria of ionic liquids with magnetic properties. ${ }^{69}$ Herein, we found that $\mathrm{T}_{\mathrm{g}}$ (in ${ }^{\circ} \mathrm{C}$ ) value for the ILs as follows, $\left[\mathrm{C}_{4} \mathrm{mim}\right]\left[\mathrm{FeCl}_{4}\right]=-87^{\circ} \mathrm{C}$ and $\left[\mathrm{C}_{4} \mathrm{mim}\right]_{2}\left[\mathrm{MnCl}_{4}\right]=-52{ }^{\circ} \mathrm{C} .{ }^{70}$ The degradation temperature $\left(\mathrm{T}_{\mathrm{d}}\right)$ of ILs was measured from TGA and first change at initial state between $100^{\circ}$ to $120^{\circ} \mathrm{C}$ which indicates the hygroscopic nature of the ILs. Beyond this temperature, major mass loss was observed which correlates with the thermal degradation of the ILs. ${ }^{71}$ Here found $\mathrm{T}_{\mathrm{d}}$ value for, $\left[\mathrm{C}_{4} \mathrm{mim}\right]\left[\mathrm{FeCl}_{4}\right]=266$ ${ }^{\circ} \mathrm{C}$, and $\left[\mathrm{C}_{4} \mathrm{mim}\right]_{2}\left[\mathrm{MnCl}_{4}\right]=353{ }^{\circ} \mathrm{C}$.

\subsection{Catalytic efficiency of ILs for pyrazole synthesis}

After the synthesis of these transition metal-based ionic liquids, we tried to show the practical importance and application of them in synthetic organic chemistry. Due to the Lewis acidic nature of these ILs, we used them for the synthesis of pyrazole moieties, which are available in many biologically active molecules and drug intermediates like Celebrex, Viagra, Fenpyroximate and Acomplia, etc.

\subsection{General reaction procedure for pyrazole synthesis}

In a round bottom flask, a mixture of hydrazine derivative (1 mmol) and 1,3-diketone $(1.2 \mathrm{mmol})$ and $\left[\mathrm{C}_{4} \mathrm{mim}\right]\left[\mathrm{FeCl}_{4}\right]$ $(1.5 \mathrm{~mL})$ was added and then allowed to stir at room temperature for the given time period as mentioned in Table 2. The progress of the reaction was monitored by TLC. After completion of the reaction, it was extracted with ethyl

Table 1. Optimization of the catalytic system for the pyrazole synthesis. ${ }^{\text {a }}$

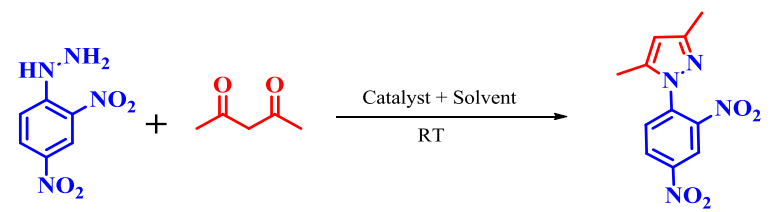

\begin{tabular}{lllll}
\hline Entry & \multicolumn{1}{c}{ Catalyst } & \multicolumn{1}{c}{ Solvent } & Time (h) & Yield $^{\mathrm{b}}(\%)$ \\
\hline 1 & $\mathrm{No} \mathrm{Catalyst}$ & Water & 12 & - \\
$2^{\mathrm{c}}$ & $\mathrm{FeCl}_{3}$ & Water & 8 & 30 \\
3 & Solvent itself as catalyst & {$\left[\mathrm{C}_{4} \mathrm{mim}\right]\left[\mathrm{BF}_{4}\right]$} & 8 & - \\
4 & Solvent itself as catalyst & {$\left[\mathrm{C}_{2} \mathrm{mim}\right][\mathrm{OH}]$} & 8 & - \\
5 & Solvent itself as catalyst & {$\left[\mathrm{C}_{4} \mathrm{mim}\right] 2\left[\mathrm{MnCl}_{4}\right]$} & 8 & 50 \\
6 & Solvent itself as catalyst & {$\left[\mathrm{C}_{4} \mathrm{mim}\right]\left[\mathrm{FeCl}_{4}\right]$} & 4 & 90 \\
\hline
\end{tabular}

a Reaction condition: 2,4-dinitrophenylhydrazine (1 mmol), acetylacetone $(1.2 \mathrm{mmol})$, catalyst + solvent $(1.5 \mathrm{~mL})$ at room temperature. ${ }^{\mathrm{b}}$ Isolated yield. ${ }^{\mathrm{c}} 10 \mathrm{~mol} \%$ of $\mathrm{FeCl}_{3}$ is used. 
acetate $(3 \times 20 \mathrm{~mL})$, washed with distilled water and brine solution, dried over anhydrous sodium sulfate and concentrated under reduced pressure. The resulting residue was purified through silica gel column chromatography (15-20\% EtOAc/hexane) to get the desired product.

\section{Results and Discussion}

For pyrazole synthesis, the reaction of 2,4-dinitrophenylhydrazine with acetylacetone was considered a model reaction (Table 1). Initially, the reaction was carried out in the presence of water without any catalyst; the reaction did not proceed at all even after $12 \mathrm{~h}$ (Table 1, entry 1). The reaction was also carried out in presence of neutral ionic liquid $\left(\left[\mathrm{C}_{4} \mathrm{mim}\right]\left[\mathrm{BF}_{4}\right]\right)$ and basic ionic liquid, $\left[\mathrm{C}_{2} \mathrm{mim}\right][\mathrm{OH}]$ but the reaction did not afford any product even after $8 \mathrm{~h}$ indicating the necessity of the acidic condition (Table 1, entries 3, 4). Using a well-known Lewis acid, $\mathrm{FeCl}_{3}$ the reaction devoted $30 \%$ yield of the product after $8 \mathrm{~h}$ (Table 1, entry 2). The use of transition metal-based ionic liquid $\left[\mathrm{C}_{4} \mathrm{mim}\right]_{2}\left[\mathrm{MnCl}_{4}\right]$ afforded $50 \%$ yields after $8 \mathrm{~h}$ (Table 1, entry 5) while the best results were obtained by using $\left[\mathrm{C}_{4} \mathrm{mim}\right]\left[\mathrm{FeCl}_{4}\right]$ as the catalytic media affording $90 \%$ yields of the desired product at room temperature (Table 1, entry 6) and used for further studies.

With the optimized condition in hand (Table 1, entry 6), we turned our focus to extend the substrate scope of this simple condensation between functionalized hydrazines and 1,3-diketones (Table 2). It is noteworthy that electron-rich, electron-deficient and heteroatom hydrazines showed outstanding reactivity and equipped the desired products with greater yields

Table 2. Effect of the substituent on pyrazole synthesis. ${ }^{\text {a }}$

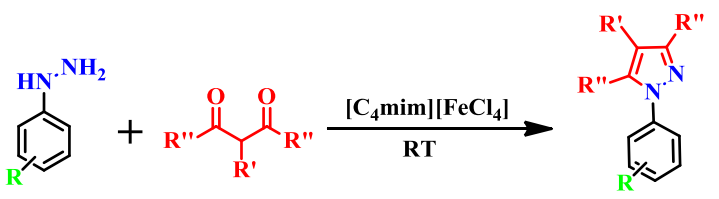

\begin{tabular}{|c|c|c|c|c|}
\hline Entry & $\mathrm{R}$ & $\mathrm{R}^{\prime}$ Or $\mathrm{R}^{\prime \prime}$ & Time (h) & Yield $^{\mathrm{b}}(\%)$ \\
\hline 1 & 2,4-dinitro & $\mathrm{R}^{\prime}=\mathrm{H}, \mathrm{R}^{\prime \prime}=\mathrm{CH}_{3}$ & 4 & 90 \\
\hline 2 & $\overrightarrow{\mathrm{H}}$ & $\mathrm{R}^{\prime}=\mathrm{H}, \mathrm{R}^{\prime \prime}=\mathrm{CH}_{3}$ & 3 & 95 \\
\hline 3 & $4-\mathrm{CF}_{3}$ & $\mathrm{R}^{\prime}=\mathrm{H}, \mathrm{R}^{\prime \prime}=\mathrm{CH}_{3}$ & 3 & 82 \\
\hline 4 & $4-\mathrm{CN}$ & $\mathrm{R}^{\prime}=\mathrm{H}, \mathrm{R}^{\prime \prime}=\mathrm{CH}_{3}$ & 4 & 85 \\
\hline 5 & $4-\mathrm{Cl}$ & $\mathrm{R}^{\prime}=\mathrm{H}, \mathrm{R}^{\prime \prime}=\mathrm{CH}_{3}$ & 3 & 88 \\
\hline 6 & $\mathrm{Ph}$ & $\mathrm{R}^{\prime}=\mathrm{Cl}, \mathrm{R}^{\prime \prime}=\mathrm{CH}_{3}$ & 4 & 78 \\
\hline 7 & $4-\mathrm{Br}$ & $\mathrm{R}^{\prime}=\mathrm{Cl}, \mathrm{R}^{\prime \prime}=\mathrm{CH}_{3}$ & 4 & 83 \\
\hline 8 & $4-\mathrm{CH}_{3}$ & $\mathrm{R}^{\prime}=\mathrm{Cl}, \mathrm{R}^{\prime \prime}=\mathrm{CH}_{3}$ & 3 & 74 \\
\hline 9 & $4-\mathrm{CF}_{3}$ & $\mathrm{R}^{\prime}=\mathrm{Cl}, \mathrm{R}^{\prime \prime}=\mathrm{CH}_{3}$ & 3.5 & 88 \\
\hline 10 & $\mathrm{Ph}$ & $\mathrm{R}^{\prime}=\mathrm{C}_{2} \mathrm{H}_{5}, \mathrm{R}^{\prime \prime}=\mathrm{CH}_{3}$ & 3 & 78 \\
\hline 11 & $4-\mathrm{Cl}$ & $\mathrm{R}^{\prime}=\mathrm{Cl}, \mathrm{R}^{\prime \prime}=\mathrm{CH}_{3}$ & 4 & 72 \\
\hline 12 & $\mathrm{Ph}$ & $\mathrm{R}^{\prime}=\mathrm{CH}_{3}, \mathrm{R}^{\prime \prime}=\mathrm{CH}_{3}$ & 3 & 95 \\
\hline 13 & $4-\mathrm{Br}$ & $\mathrm{R}^{\prime}=\mathrm{CH}_{3}, \mathrm{R}^{\prime \prime}=\mathrm{CH}_{3}$ & 3 & 73 \\
\hline 14 & $4-\mathrm{Br}$ & $\mathrm{R}^{\prime}=\mathrm{C}_{2} \mathrm{H}_{5}, \mathrm{R}^{\prime \prime}=\mathrm{CH}_{3}$ & 4 & 50 \\
\hline 15 & $4-\mathrm{CH}_{3}$ & $\mathrm{R}^{\prime}=\mathrm{CH}_{3}, \mathrm{R}^{\prime \prime}=\mathrm{CH}_{3}$ & 4 & 83 \\
\hline 16 & $4-\mathrm{CH}_{3}$ & $\mathrm{R}^{\prime}=\mathrm{C}_{2} \mathrm{H}_{5}, \mathrm{R}^{\prime \prime}=\mathrm{CH}_{3}$ & 4 & 74 \\
\hline 17 & $4-\mathrm{Cl}$ & $\mathrm{R}^{\prime}=\mathrm{CH}_{3}, \mathrm{R}^{\prime \prime}=\mathrm{CH}_{3}$ & 3 & 86 \\
\hline 18 & $4-\mathrm{CN}$ & $\mathrm{R}^{\prime}=\mathrm{Cl}, \mathrm{R}^{\prime \prime}=\mathrm{CH}_{3}$ & 4 & 72 \\
\hline 19 & $4-\mathrm{NO}_{2}$ & $\mathrm{R}^{\prime}=\mathrm{H}, \mathrm{R}^{\prime \prime}=\mathrm{CH}_{3}$ & 4 & 50 \\
\hline 20 & $4-\mathrm{CN}^{2}$ & $\mathrm{R}^{\prime}=\mathrm{C}_{2} \mathrm{H}_{5}, \mathrm{R}^{\prime \prime}=\mathrm{CH}_{3}$ & 4 & 68 \\
\hline 21 & $4-\mathrm{Br}$ & $\mathrm{R}^{\prime}=\mathrm{H}, \mathrm{R}^{\prime \prime}=\mathrm{CH}_{3}$ & 2 & 92 \\
\hline 22 & 2-hydrazino pyridine & $\mathrm{R}^{\prime}=\mathrm{C}_{2} \mathrm{H}_{5}, \mathrm{R}^{\prime \prime}=\mathrm{CH}_{3}$ & 3 & 90 \\
\hline 23 & $4-\mathrm{CF}_{3}$ & $\mathrm{R}^{\prime}=\mathrm{H}, \mathrm{R}^{\prime \prime}=\mathrm{C}_{2} \mathrm{H}_{5}$ & 3 & 85 \\
\hline 24 & 2-furoic hydrazide & $\mathrm{R}^{\prime}=\mathrm{H}, \mathrm{R}^{\prime \prime}=\mathrm{C}_{2} \mathrm{H}_{5}$ & 3 & 94 \\
\hline
\end{tabular}

${ }^{a}$ Reaction condition: Hydrazine derivative $(1 \mathrm{mmol})$, 1,3-dicarbonyl derivative $(1.2 \mathrm{mmol})$, $\left[\mathrm{C}_{4} \mathrm{mim}\right]\left[\mathrm{FeCl}_{4}\right](1.5 \mathrm{~mL})$ at room temperature.

${ }^{\mathrm{b}}$ Isolated yields. 
at room temperature in shorter reaction times. (Table 2, entries 1-24).

In order to illustrate the practical appliances of this transition metal-based ionic liquid, it was very much essential to reuse and recycle this ionic liquid system (Table 3). The reaction of 2,4-dinitrophenylhydrazine with acetylacetone was carried out to check reusability and recyclability of the catalyst under optimal reaction condition. After the reaction, the catalyst can be separated easily due to its magnetic nature and solubility behavior. It was seen that the ionic liquid could be recovered easily since it is insoluble in organic solvents and reused up to three times for the pyrazole synthesis without loss of its activity (Table 3, entries $1-3)$. But after $3^{\text {rd }}$ cycle, catalytic activity of the system goes on decreasing and it may be due to the small amount of loss of $\mathrm{FeCl}_{3}$ attached to the ionic liquids in each batch which was confirmed from the ICP-OES analyses of the fresh and reused ionic liquid. We also found that the percentage of $\mathrm{Fe}$ was $14 \%$ in the fresh ionic liquid whereas it was $11 \%$ in reused $\left[\mathrm{C}_{4}\right.$ $\operatorname{mim}]\left[\mathrm{FeCl}_{4}\right]$ after the $4^{\text {th }}$ cycle (Table 3 , entry 4 ).

The ionic liquid does not undergo decomposition during continuous recycling and no structural changes were observed and it was confirmed by the Raman spectra and ICP-OES analysis of the reused ionic liquid. In the fresh ionic liquid, there was a peak at $337 \mathrm{~cm}^{-1}$ which is characteristic of total symmetric vibration $\left(\mathrm{A}_{1}\right)$ mode for $\mathrm{Fe}-\mathrm{Cl}$ bond in $\left[\mathrm{FeCl}_{4}\right]^{-}$anion and after the fourth cycle, it was found at $334 \mathrm{~cm}^{-1}$ (Figure 4). Moreover, from the ICP-OES analysis, \% of $\mathrm{Fe}$ was found to be $14 \%$ in the fresh ionic liquid whereas $11 \% \mathrm{Fe}$ was available in reused $\left[\mathrm{C}_{4-}\right.$ $\operatorname{mim}]\left[\mathrm{FeCl}_{4}\right]$ after the $4^{\text {th }}$ cycle.

Table 3. Test of recyclability. ${ }^{\mathrm{a}}$

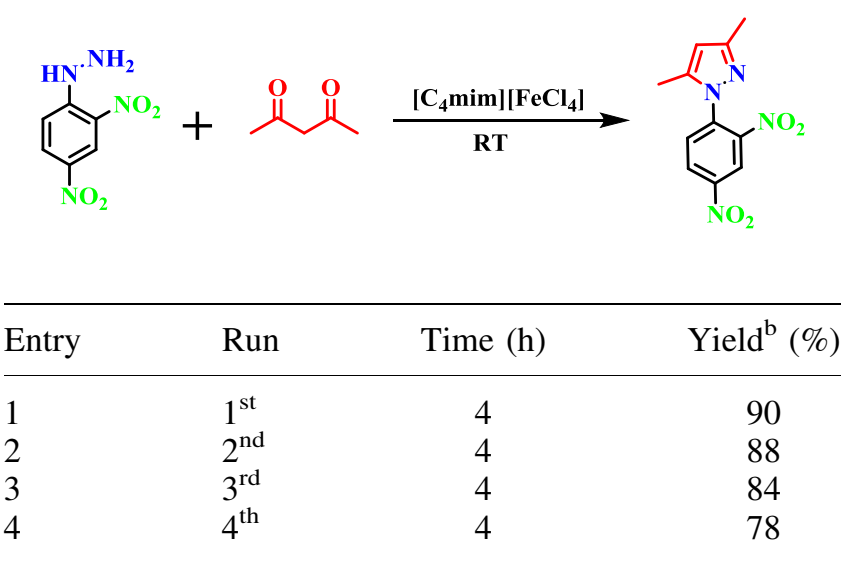

${ }^{a}$ Reaction Conditions: 2,4-dinitrophenylhydrazine (1 $\mathrm{mmol})$, acetylacetone $(1.2 \mathrm{mmol}),\left[\mathrm{C}_{4} \mathrm{mim}\right]\left[\mathrm{FeCl}_{4}\right](1.5$ $\mathrm{mL})$ at room temperature.

${ }^{b}$ Isolated yields after column chromatography.

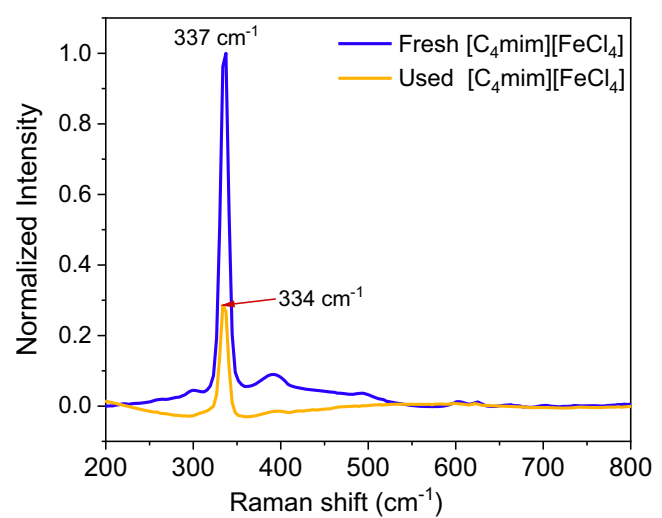

Figure 4. Raman spectra of the reused $\left[\mathrm{C}_{4} \mathrm{mim}\right]\left[\mathrm{FeCl}_{4}\right]$ after $4^{\text {th }}$ cycles.

A plausible mechanism has been proposed after getting the experimental outcomes. Scheme 1 shows probable steps for the synthesis of substituted pyrazoles in presence of $\mathrm{Fe}$ containing ionic liquid. Initially, in equilibrium $\left[\mathrm{FeCl}_{4}\right]^{-}$breaks as the combination of $\mathrm{FeCl}_{3}$ and $\mathrm{Cl}^{-}$anion, and so formed $\mathrm{FeCl}_{3}$ would act as a competent Lewis acid making an interaction with the lone pair of the oxygen atom of the acetylacetone molecule thereby increasing the electrophilicity of that carbon. Then the electrophilic centre is attracted by the basic nitrogen atom of hydrazine and subsequently rearranges to a hydrazone intermediate. The remaining carbonyl group of this hydrazone intermediate again follows similar steps and rearranges to pyrazole moiety followed by the loss of a water molecule. The reaction proceeds through the interaction of Lewis acidic Fe(III) ion and the nucleophilic oxygen atom of the 1,3-diketones and it was well-established by various research groups. ${ }^{72-74}$

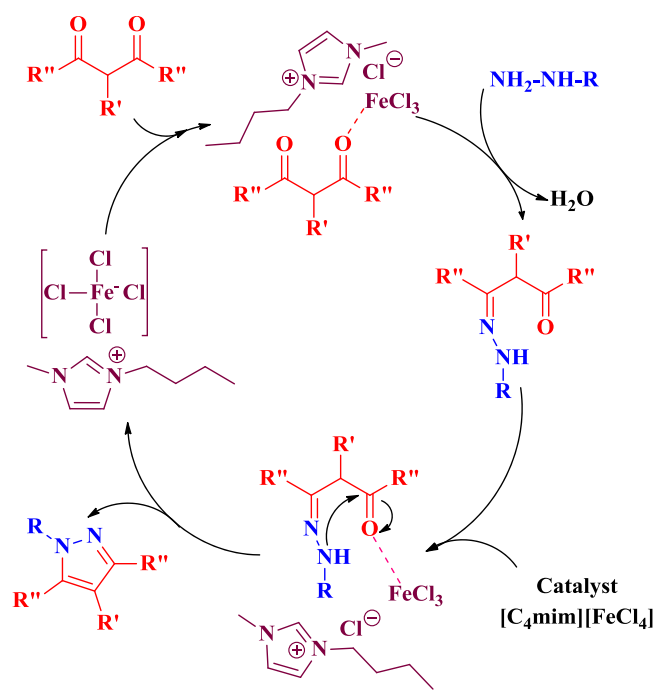

Scheme 1. Plausible reaction mechanism. 
Moreover, the other parts of the ionic liquid such as $\left[\mathrm{C}_{4} \mathrm{mim}\right]^{+}$and $\mathrm{Cl}^{-}$anion create a supportive environment in the reaction mechanism.

\section{Conclusions}

In conclusion, a facile, convenient and quick method for pyrazole synthesis was presented using metalcontaining imidazole based ionic liquids. The $\left[\mathrm{C}_{4-}\right.$ $\operatorname{mim}]\left[\mathrm{FeCl}_{4}\right]$ exhibits a dual role of solvent and catalyst for the synthesis of pyrazoles, with adequate yields in short reaction time at room temperature. The use of transition metal-based ionic liquid system can be considered as relatively less toxic, inexpensive, energy saving, efficient, non-corrosive and eliminates tedious catalyst synthesis steps.

\section{Supplementary Information (SI)}

The general experimental procedure, NMR and MS spectra for all compounds with full characterization are available as supplementary information at www.ias.ac.in/chemsci.

\section{Acknowledgements}

M. K. is thankful to UGC for UGC-BSR fellowship. D. S. is thankful to DST, New Delhi, India for a research grant [No. EMR/2016/002345]. The authors also acknowledge the Department of Science and Technology for financial assistance under DST-FIST programme and UGC, New Delhi for Special Assistance Programme (UGC-SAP) to the Department of Chemistry, Dibrugarh University.

\section{References}

1. Blesic M, Lopes J N C, Gomes M F C and Rebelo L P N 2010 Solubility of alkanes, alkanols and their fluorinated counterparts in tetraalkylphosphonium ionic liquids Phys. Chem. Chem. Phys. 129685

2. Lopes J N C and Padua A A H 2006 Nanostructural organization in ionic liquids J. Phys. Chem. B 1103330

3. S Zhang, J Wang, X Lu and Q Zhou (Eds.) 2014 Structures and Interactions of Ionic Liquids (Heidelberg: Springer)

4. Rogers R D and Seddon K R 2003 Ionic liquids-solvents of the future? Science $\mathbf{3 0 2} 792$

5. Kunz W and Häckl K 2016 The hype with ionic liquids as solvents Chem. Phys. Lett. 6616

6. Welton T 1999 Room-temperature ionic liquids. Solvents for synthesis and catalysis Chem. Rev. 992071

7. Weingartner H 2008 Understanding ionic liquids at the molecular level: facts, problems, and controversies Angew. Chem. Int. Ed. 47654

8. Wasserschied P and Keim W 2000 Ionic liquids-new "solutions" for transition metal catalysis Angew. Chem. Int. Ed. 393772
9. Diallo A O, Len C, Morgan A B and Marlair G 2012 Revisiting physico-chemical hazards of ionic liquids Sep. Purif. Technol. 97228

10. Diallo A O, Morgan A B, Len C and Marlair G 2013 An innovative experimental approach aiming to understand and quantify the actual fire hazards of ionic liquids Energy. Environ. Sci. 6699

11. Chancelier L, Diallo A O, Santini C C G. Marlair, Gutel T, Mailley S and Len C 2014 Targeting adequate thermal stability and fire safety in selecting ionic liquid-based electrolytes for energy storage Phys. Chem. Chem. Phys. 161967

12. Pervulescu V I and Hardacre C 2007 Catalysis in ionic liquids Chem. Rev. 1072615

13. (a) Sheldon $\mathrm{R} 2001$ Catalytic reactions in ionic liquids Chem. Commun. 2399; (b) Jeyaveeran J C, Praveen C, Arun Y, Prince A A M and Perumal P T 2016 Cycloisomerization of acetylenic oximes and hydrazones under gold catalysis: Synthesis and cytotoxic evaluation of isoxazoles and pyrazoles J. Chem. Sci. 12873

14. (a) Ebrahimi J, Mohammadi A, Pakjoo V, Bahramzade E and Habibi A 2012 Highly efficient solvent-free synthesis of pyranopyrazoles by a Brønsted-acidic ionic liquid as a green and reusable catalyst J. Chem. Sci. 124 1013; (b) Boruah P R, Koiri M J, Bora U and Sarma D 2014 A new recyclable/reusable ionic liquid/ $\mathrm{LiCl}$ system for Suzuki-Miyaura cross coupling reactions Tetrahedron Lett. 552423

15. (a) Elhaj E, Wang H and Gu Y 2019 Functionalized quaternary ammonium salt ionic liquids (FQAILs) as an economic and efficient catalyst for synthesis of glycerol carbonate from glycerol and dimethyl carbonate Mol. Catal. 468 19; (b) Ali A A, Konwar M, Chetia M and Sarma D 2016 [Bmim] OH mediated Cucatalyzed azide-alkyne cycloaddition reaction: A potential green route to 1,4-disubstituted 1,2,3-triazoles Tetrahedron Lett. 575661

16. (a) Yang C, Liu M, Zhang J, Wang X, Jiang Y and Sun J 2018 Facile synthesis of DBU-based ionic liquids cooperated with $\mathrm{ZnI}_{2}$ as catalysts for efficient cycloaddition of $\mathrm{CO}_{2}$ to epoxides under mild and solvent-free conditions Mol. Catal. 450 39; (b) Konwar M, Khupse N D, Saikia P J and Sarma D 2018 A potential greener protocol for peptide coupling reactions using recyclable/reusable ionic liquid $\left[\mathrm{C}_{4^{-}}\right.$ $\mathrm{DABCO}]\left[\mathrm{N}(\mathrm{CN})_{2}\right]$ J. Chem. Sci. 13053

17. Khalafi-Nezhad A and Mohammadi S 2014 Chitosan supported ionic liquid: a recyclable wet and dry catalyst for the direct conversion of aldehydes into nitriles and amides under mild conditions RSC Adv. 413782

18. (a) Prodius D, Macaev F, Stingaci E, Pogrebnoi V, Mereacre V, Novitchi G, Kostakis G E, Anson C E and Powell A K 2013 Catalytic "triangles": binding of iron in task-specific ionic liquids Chem. Commun. 49 1915; (b) Nagpal R, Arora S and Chauhan S M 2016 Efficient synthesis of metallated thioporphyrazines in task specific ionic liquids and their spectroscopic investigation of binding with selected transition metal ions $J$. Chem. Sci. 1281417

19. Leng Y, Wang J, Zhu D, Ren X, Ge H and Shen L 2009 Heteropolyanion-based ionic liquids: reaction-induced 
self-separation catalysts for esterification Angew. Chem. Int. Ed. 48174

20. Sarkar A, Roy R and Chakraborti A K 2011 Ionic liquid catalysed reaction of thiols with $\alpha, \beta$-unsaturated carbonyl compounds-remarkable influence of the C-2 hydrogen and the anion Chem. Commun. 474538

21. Qiao K and Yokoyama C 2004 Novel acidic ionic liquids catalytic systems for Friedel-Crafts alkylation of aromatic compounds with alkenes Chem. Lett. 33472

22. Hitchcock P B, Seddon K R and Welton T 1993 Hydrogen-bond acceptor abilities of tetrachlorometalate (II) complexes in ionic liquids J. Chem. Soc. Dalton Trans. 172639

23. Hayashi S and Hamaguchi H 2004 Discovery of a Magnetic Ionic Liquid [bmim] $\mathrm{FeCl}_{4}$ Chem. Lett. 33 1590

24. Abbot A P, Capper G, Davies D L and Rasheed R 2004 Ionic liquids based upon metal halide/substituted quaternary ammonium salt mixtures Inorg. Chem. 433447

25. Duan Z, Gu Y and Deng Y 2006 Green and moisturestable Lewis acidic ionic liquids (choline chloride. $\mathrm{xZnCl2}$ ) catalyzed protection of carbonyls at room temperature under solvent-free conditions Catal. Commun. 7651

26. (a) Yin D, Li C, Tao L, Yu N, Hu S and Yin D 2006 Synthesis of diphenylmethane derivatives in Lewis acidic ionic liquids J. Mol. Catal. A: Chem. 245 260; (b) Prikhod'ko S A, Popov A G and Adonin N Y 2018 Effects arising from the replacement of aprotic dipolar solvents with ionic liquids in the nickel-catalyzed reduction of aryl chlorides Mol. Catal. 46119

27. Dale D J, Dunn P J, Golightly C, Hughes M L, Levett P C, Pearce A K, Searle P M, Ward G and Wood A S 2000 The chemical development of the commercial route to sildenafil: a case history The chemical development of the commercial route to sildenafil: A case history Org. Process. Res. Dev. 417

28. Dai H, Chen J, Li G, Ge S, Shi Y, Fang Y and Ling Y 2017 Design, synthesis, and bioactivities of novel oxadiazole-substituted pyrazole oximes Bioorg. Med. Chem. Lett. 27950

29. Alam R, Wahi D, Singh R, Sinha D, Tandon V, Grover A and Rahisuddin 2016 Design, synthesis, cytotoxicity, HuTopoII $\alpha$ inhibitory activity and molecular docking studies of pyrazole derivatives as potential anticancer agents Bioorg. Chem. 6977

30. Chougala B M, Samundeeswari S, Holiyachi M, Shastri L A, Dodamani S, Jalalpure S, Dixit S R, Joshi S D and Sunagar V A 2017 Synthesis, characterization and molecular docking studies of substituted 4-coumarinylpyrano[2,3-c]pyrazole derivatives as potent antibacterial and anti-inflammatory agents Eur. J. Med. Chem. 125101

31. Singer R A, Caron S, McDermott R E, Arpin R and Do N M 2003 Alternative biarylphosphines for use in the palladium-catalyzed amination of aryl halides Synthesis 111727

32. Eisenwiener A, Neuburger M and Kaden T A 2007 $\mathrm{Cu}^{2+}$ and $\mathrm{Pt}^{2+}$ complexes of pyrazole and triazole based dinucleating ligands Dalton Trans. 218

33. Yang D, Sun P, Wei W, Meng L, He L, Fang B, Jiang W and Wang H 2016 Metal-free iodine-catalyzed direct cross-dehydrogenative coupling (CDC) between pyrazoles and thiols Org. Chem. Front. 31457

34. Terrett N K, Bell A S, Brown D and Ellis P 1996 Sildenafil (VIAGRATM), a potent and selective inhibitor of type 5 cGMP phosphodiesterase with utility for the treatment of male erectile dysfunction Bioorg. Med. Chem. Lett. 61819

35. Pfefferkorn J A, Choi C, Larsen S D, Auerbach B, Hutchings R, Park W, Askew V, Dillon L, Hanselman J C, Lin Z, Lu G H, Robertson A, Sekerke C, Harris M S, Pavlovsky A, Bainbridge G, Caspers N, Kowala M and Tait B D 2008 Substituted Pyrazoles as Hepatoselective HMG-CoA Reductase Inhibitors: Discovery of (3R,5R)-7-[2-(4-Fluoro-phenyl)-4-isopropyl-5-(4methyl-benzylcarbamoyl)-2H-pyrazol-3-yl]-3,5-dihydroxyheptanoic Acid (PF-3052334) as a Candidate for the Treatment of Hypercholesterolemia J. Med. Chem. 5131

36. Catalan J, Fabero F, Claramunt R M, Maria M D S, Foces-Foces M C, Cano F H, Martinez-Ripoll M, Elguero J and Sastre R 1992 New ultraviolet stabilizers: 3-and 5-(2'-hydroxyphenyl) pyrazoles J. Am. Chem. Soc. 1145039

37. Catalan J, Fabero F, Guijano M S, Claramunt R M, Maria M D S, Foces-Foces M C, Cano F H, Elguero J and Sastre R 1990 Photoinduced intramolecular proton transfer as the mechanism of ultraviolet stabilizers: a reappraisal J. Am. Chem. Soc. 112747

38. Dorlars A, Schellhammer C W and Schroeder J 1975 Heterocycles as structural units in new optical brighteners Angew. Chem. Int. Ed. 14665

39. Yang Z, Zhang K, Gong F, Li S, Chen J, Ma J S, Sobenina L N, Mikhaleva A I, Trofimov B A and Yang G 2011 A highly selective fluorescent sensor for fluoride anion based on pyrazole derivative: Naked eye "no-yes" detection J. Photochem. Photobiol. A 21729

40. Li J, Zhou J H, Li Y Z, Weng L H, Chen X T, Yu Z and Xue Z 2004 Synthesis and structures of two luminescent $\mathrm{Zn}$ (II) complexes with pyrazole and carboxylate ligands Inorg. Chem. Commun. 7538

41. Mayoral M J, Ovejero P, Campo J A, Heras J V, Pinilla E, Torres M R, Lodeiro C and Cano M 2008 Silver and gold luminescent metallomesogens based on pyrazole ligands Dalton Trans. 6912

42. Heller S T and Natarajan S R 2006 1, 3-Diketones from acid chlorides and ketones: a rapid and general one-pot synthesis of pyrazoles Org. Lett. 82675

43. Wang Z and Qin H 2004 Solventless syntheses of pyrazole derivatives Green Chem. 690

44. Chen B, Zhu C, Tang Y and Ma S 2014 Copper-mediated pyrazole synthesis from 2, 3-allenoates or 2-alkynoates, amines and nitriles Chem. Commun. 50 7677

45. Armstrong A, Jones L H, Knight J D and Kelsey R D 2005 Oxaziridine-mediated amination of primary amines: scope and application to a one-pot pyrazole synthesis Org. Lett. 7713

46. Escribano F C, Alcdntara M P D and Gomez-Sanchez A 1988 Heterocycle formation from 1, 3-dinitroalkanes. A novel pyrazole synthesis Tetrahedron Lett. 296001

47. Wei W, Wang Z, Yang X, Yu W and Chang J 2017 Divergent Synthesis of 1H-Indazoles and 1H-Pyrazoles 
from Hydrazones via Iodine-Mediated Intramolecular Aryl and $\mathrm{sp}^{3} \mathrm{C}-\mathrm{H}$ Amination Adv. Synth. Catal. 359 3378

48. Deng X and Mani N S 2008 Regioselective Synthesis of 1,3,5-Tri- and 1,3,4,5-Tetrasubstituted Pyrazoles from N-Arylhydrazones and Nitroolefins J. Org. Chem. 732412

49. Punner F, Sohtome Y and Sodeoka M 2016 Solventdependent copper-catalyzed synthesis of pyrazoles under aerobic conditions Chem. Commun. 5214093

50. Tang M, Zhang W and Kong Y 2013 DABCO-promoted synthesis of pyrazoles from tosylhydrazones and nitroalkenes Org. Biomol. Chem. 116250

51. Zhang H, Wei Q, Zhu G, Qu J and Wang B 2016 A facile and expeditious approach to substituted $1 \mathrm{H}$ pyrazoles catalyzed by iodine Tetrahedron Lett. 57 2633

52. Polshettiwar V and Varma R S 2008 Greener and rapid access to bio-active heterocycles: room temperature synthesis of pyrazoles and diazepines in aqueous medium Tetrahedron Lett. 49397

53. Nikpassand $\mathrm{M}$, Mamaghani $\mathrm{M}$, Tabatabaeian $\mathrm{K}$ and Abiazi M K 2009 KSF: an efficient catalyst for the regioselective synthesis of 1, 5-diaryl pyrazoles using Baylis-Hillman adducts Mol. Divers. 13389

54. Choudhary S, Muthyala M K, Parang K and Kumar A 2014 Ionic liquid-supported sulfonyl hydrazine: a useful reagent for traceless synthesis of pyrazoles $\mathrm{Org}$. Chem. Front. 1683

55. Yuan B, Zhang F, Li Z, Yang S and Yan R 2016 $\mathrm{AgNO}_{2}$ as the NO Source for the Synthesis of Substituted Pyrazole N-Oxides from N-Propargylamines Org. Lett. 185928

56. Ahmed M S M, Kobayashi K and Mori A 2005 Onepot construction of pyrazoles and isoxazoles with palladium-catalyzed four-component coupling Org. Lett. 7 4487

57. Pal G, Paul S, Ghosh P P and Das A R 2014 PhIO promoted synthesis of nitrile imines and nitrile oxides within a micellar core in aqueous media: a regiocontrolled approach to synthesizing densely functionalized pyrazole and isoxazoline derivatives $R S C A d v .48300$

58. Zolfigol M A, Afsharnadery F, Baghery S, Salehzadeh $S$ and Maleki F 2015 Catalytic applications of $\left\{[\mathrm{HMIM}] \mathrm{C}\left(\mathrm{NO}_{2}\right)_{3}\right\}$ : as a nano ionic liquid for the synthesis of pyrazole derivatives under green conditions and a mechanistic investigation with a new approach RSC Adv. 575555

59. Bora P P, Bihani M and Bez G 2013 Multicomponent synthesis of dihydropyrano [2, 3-c] pyrazoles catalyzed by lipase from Aspergillus niger J. Mol. Catal. B: Enzym. 9224

60. Shabalala N, Pagadala R and Jonnalagadda S B 2015 Ultrasonic-accelerated rapid protocol for the improved synthesis of pyrazoles Ultrason. Sonochem. 27423

61. Polshettiwar V and Varma R S 2010 Nano-organocatalyst: magnetically retrievable ferrite-anchored glutathione for microwave-assisted Paal-Knorr reaction,
aza-Michael addition, and pyrazole synthesis Tetrahedron 661091

62. Shelke S N, Bankar S R, Mhaske G R, Kadam S S, Murade D K, Bhorkade S B, Rathi A K, Bundaleski N, Teodoro O M N D, Zboril R, Varma R S and Gawande M B 2014 Iron Oxide-Supported Copper Oxide Nanoparticles (Nanocat-Fe-CuO): Magnetically Recyclable Catalysts for the Synthesis of Pyrazole Derivatives, 4-Methoxyaniline, and Ullmann-type Condensation Reactions ACS Sustain. Chem. Eng. 21699

63. Del Sesto R E, McCleskey T M, Burrell A K, Baker G A, Thompson J D, Scott B L, Wilkes J S and Williams P 2008 Structure and magnetic behavior of transition metal based ionic liquids Chem. Commun. 4447

64. Bwambok D K, Thuo M M, Atkinson M B, Mirica K A, Shapiro N D and Whitesides G M 2013 Paramagnetic ionic liquids for measurements of density using magnetic levitation Anal. Chem. 858442

65. Bäcker T, Breunig O, Valldor M, Merz K, Vasylyeva V and Mudring A V 2011 In-Situ Crystal Growth and Properties of the Magnetic Ionic Liquid $\left[\mathrm{C}_{2}\right.$ $\operatorname{mim}]\left[\mathrm{FeCl}_{4}\right]$ Cryst. Growth. Des. 112564

66. Slawomir P and Anja-Verena M 2010 Synthesis, Structure, and Physico-optical Properties of Manganate (II)-Based Ionic Liquids Chem. Eur. J. 163355

67. Smith M C, Xiao Y, Wang H, George S J, Coucouvanis D, Koutmos M, Sturhahn W, Alp E E, Zhao J and Cramer S P 2005 Normal-Mode Analysis of $\mathrm{FeCl}_{4}^{-}$and $\mathrm{Fe}_{2} \mathrm{~S}_{2} \mathrm{Cl}_{4}^{2-}$ via Vibrational Mössbauer, Resonance Raman, and FTIR Spectroscopies Inorg. Chem. 445562

68. Sitze M S, Schreiter E R, Patterson E V and Freeman R G 2001 Ionic Liquids Based on $\mathrm{FeCl}_{3}$ and $\mathrm{FeCl}_{2}$. Raman Scattering and ab Initio Calculations Inorg. Chem. 402298

69. Li M, De Rooy S L, Bwambok D K, El-Zahab B, DiTusa J F and Warner I M 2009 Magnetic chiral ionic liquids derived from amino acids Chem. Commun. 45 6922

70. Yoshida Y and Saito G 2006 Influence of structural variations in 1-alkyl-3-methylimidazolium cation and tetrahalogenoferrate (III) anion on the physical properties of the paramagnetic ionic liquids J. Mater. Chem. 161254

71. Fredlake C P, Crosthwaite J M, Hert D G, Aki S N and Brennecke J F 2004 J. Chem. Eng. Data 49954

72. Bera K, Sarkar S, Biswas S, Maiti S and Jana U 2011 Iron-Catalyzed Synthesis of Functionalized 2HChromenes via Intramolecular Alkyne-Carbonyl Metathesis J. Org. Chem. 763539

73. Sarkar S, Bera K, Maiti S, Biswas S and Jana U 2013 Three-Component Coupling Synthesis of Diversely Substituted N-Aryl Pyrroles Catalyzed by Iron (III) Chloride Synth. Commun. 431563

74. Maiti S, Biswas S and Jana U 2010 Iron(III)-Catalyzed Four-Component Coupling Reaction of 1,3-Dicarbonyl Compounds, Amines, Aldehydes, and Nitroalkanes: A Simple and Direct Synthesis of Functionalized Pyrroles J. Org. Chem. 751674 